\title{
Memory disrupting effects of nonmuscle myosin II inhibition depend on the class of abused drug and brain region
}

\author{
Sherri B. Briggs, ${ }^{1,2,3}$ Ashley M. Blouin, ${ }^{1,2,3}$ Erica J. Young, ${ }^{1,2}$ Gavin Rumbaugh, ${ }^{2}$ \\ and Courtney A. Miller ${ }^{1,2}$ \\ ${ }^{1}$ Department of Metabolism \& Aging; ${ }^{2}$ Department of Neuroscience, The Scripps Research Institute, Jupiter, Florida 33458, USA
}

\begin{abstract}
Depolymerizing actin in the amygdala through nonmuscle myosin II inhibition (NMIli) produces a selective, lasting, and retrieval-independent disruption of the storage of methamphetamine-associated memories. Here we report a similar disruption of memories associated with amphetamine, but not cocaine or morphine, by NMlli. Reconsolidation appeared to be disrupted with cocaine. Unlike in the amygdala, methamphetamine-associated memory storage was not disrupted by NMIli in the hippocampus, nucleus accumbens, or orbitofrontal cortex. NMIli in the hippocampus did appear to disrupt reconsolidation. Identification of the unique mechanisms responsible for NMII-mediated, amygdala-dependent disruption of memory storage associated with the amphetamine class may enable induction of retrieval-independent vulnerability to other pathological memories.
\end{abstract}

[Supplemental material is available for this article.]

There are no FDA-approved pharmacotherapies to treat relapse for psychostimulant abuse. Persistent, drug-associated memories are an underlying core feature of substance use disorder (SUD) that can serve as powerful relapse triggers. These memories are triggered by numerous and often abstract environmental cues, making them difficult to predict and treat (Hyman et al. 2006; Milton and Everitt 2012).

Dendritic spines, which are thought to contribute to the encoding and storage of memory, undergo actin-dependent changes at the time of learning that are critical to long-term memory (Yang et al. 2009; Lai et al. 2012). Memory-dependent structural plasticity that occurs during long-term potentiation (LTP) requires actin polymerization, the process of elongating filamentous actin (F-actin) by the addition of the monomeric globular form of actin (G-actin) (Lin et al. 2005; Kramar et al. 2006). Moreover, when actin depolymerizing agents are delivered to Area CA1 of the hippocampus (CA1), basolateral amygdala complex (lateral and basolateral amygdala; BLC), infralimbic region of the prefrontal cortex (IL, PFC) or nucleus accumbens (NAc) around the time of learning, memory formation fails (Fischer et al. 2004; Mantzur et al. 2009; Rex et al. 2010; Gavin et al. 2012; Bi et al. 2015). Recently, we reported an unexpected and unique role for F-actin dynamics in the storage of memories associated with the highly addictive stimulant, methamphetamine (METH) (Young et al. $2014,2015)$. Direct actin depolymerization within the BLC produces an immediate and long-lasting disruption of METH-associated memory storage and drug seeking, along with a concomitant loss of dendritic spines, that is both independent of retrieval and selective, having no effect on memories associated with fear or food reward.

We have also previously identified nonmuscle myosin II (NMII) as a direct regulator of actin polymerization in dendritic spines (Rex et al. 2010). Indeed, as with actin depolymerization,

\footnotetext{
${ }^{3}$ These authors contributed equally to this work.

Corresponding author: cmiller@scripps.edu

Article is online at http://www.learnmem.org/cgi/doi/10.1101//m.043976.116.
}

formation of a fear memory is prevented by genetic and pharmacologic NMII inhibition (NMIIi) (Rex et al. 2010; Gavin et al. 2012). Further, NMIIi with the small molecule inhibitor Blebbistatin (Blebb), either delivered directly into the BLC or injected systemically, produces the same selective, long-lasting and retrieval-independent disruption of METH-associated memory storage and associated drug seeking (Young et al. 2014, 2016). Genetic knockdown of NMIIB, the most abundant of the three NMII isoforms in the BLC, mirrors Blebb's effects on METH-associated memory (Young et al. 2016). Given the potential of a therapeutic that could cause the long-lasting, retrieval-independent and selective loss of a drug-associated memory's storage following a single administration, a better understanding of the parameters of NMII inhibition is warranted.

In the present study, we used conditioned place preference (CPP) to determine if immediate, retrieval-independent NMIImediated memory disruption extends from METH to other drugs of abuse (morphine [MOR], cocaine [COC], and amphetamine [AMP]) and other brain regions of the neural circuit regulating METH-associated memories: CA1, the orbitofrontal cortex (OFC) of the PFC and the nucleus accumbens core (NAcc) (Chiang et al. 2009; Ricoy and Martinez 2009; Baracz et al. 2012; Keleta and Martinez 2012; Aguilar-Valles et al. 2014; Zhao et al. 2015). Furthermore, in the absence of a Blebb-induced disruption, we assessed potential Blebb effects on reconsolidation with a second, drug-free test the following day because the therapeutic potential of disrupting drug-associated memories through a blockade of reconsolidation is an area of active research in the SUD field (Lee et al. 2005; Miller and Marshall 2005; Taylor et al. 2009; Torregrossa and Taylor 2013; Tronson and Taylor 2013).

\footnotetext{
C 2017 Briggs et al. This article is distributed exclusively by Cold Spring Harbor Laboratory Press for the first 12 months after the full-issue publication date (see http://learnmem.cshlp.org/site/misc/terms.xhtml). After 12 months, it is available under a Creative Commons License (AttributionNonCommercial 4.0 International), as described at http://creativecommons. org/licenses/by-nc/4.0/.
} 
To examine the effect of NMIIi on contextual memories associated with other drugs of abuse, mice were conditioned to the opiate MOR and given a systemic vehicle (VEH) or Blebb injection 30 min prior to a drug-free preference test (Test 1) (Fig. 1A). This protocol produces an immediate and lasting disruption of METH-associated memory and context-induced METH seeking that is not dependent on retrieval (Young et al. 2014, 2016). Animals were tested again $24 \mathrm{~h}$ later, but received no additional Blebb or MOR. Detailed methods are provided in the Supplemental Material. Statistical analysis revealed that there was no significant effect of Blebb on MOR-associated memory, as both VEH and Blebb-treated animals spent more time in the $\mathrm{CS}+$ (drug-paired) versus CS - (saline-paired) compartment, (Fig. 1B,C) (VEH: Test $\times$ Compartment: $F_{(2,44)}=15.09, P \leq 0.0001$; Compartment: $F_{(1,22)}=8.575, P \leq 0.01$; Test: $F_{(2,44)}=0.9532, P>0.05$; Blebb: Test $\times$ Compartment: $F_{(2,44)}=16.07, P \leq 0.0001$; Compartment: $F_{(1,22)}=29.53, P \leq 0.0001$; Test: $\left.F_{(2,44)}=1.109, P>0.05\right)$. Post hoc analysis confirmed that Blebb had neither an immediate (Test 1), nor delayed (Test 2) effect on MOR-associated memory.

Given the lack of effect on an opioid-associated memory, we shifted to an abused drug closer in mechanism to METH, the psychostimulant COC. As with MOR, Blebb did not have an immediate effect on COC-associated memory (Fig. 1D,E; VEH: Test $\times$ Compartment: $F_{(2,56)}=24.00, P \leq 0.0001$; Compartment $F_{(1,28)}=25.14, P \leq 0.0001$; Test: $F_{(2,56)}=1.330, P>0.05$; Blebb: Test $\times$ Compartment: $F_{(2,56)}=16.37, P \leq 0.0001 ; F_{(1,28)}=8.509$, $P \leq 0.01$; Test: $\left.F_{(2,56)}=1.143, P>0.05\right)$. However, preference for the COC-paired compartment was absent at Test 2 in the Blebb group (Fig. 1E), suggesting that actin depolymerization via sys-
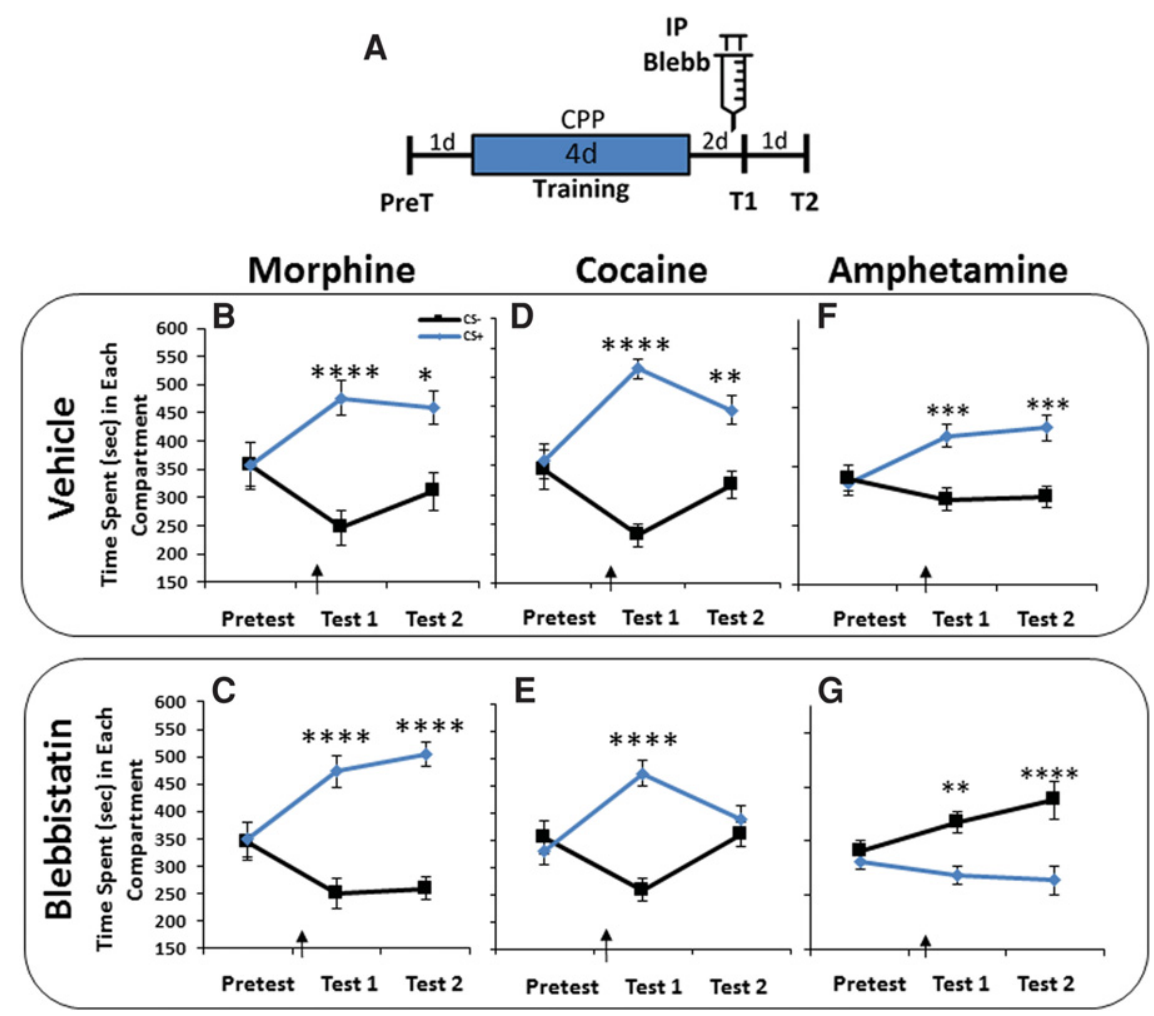

Figure 1. Nonmuscle myosin II inhibition produces an immediate disruption of amphetamine-associated memory. (A) Schematic of experimental design. The effect of systemic Blebb on the expression of $(B, C)$ MOR, $(D, E)$ COC, and $(F, G)$ AMP memory. Arrows indicate timing of Vehicle or Blebb injection. MOR: Veh $N=12$; Blebb $N=12$; COC: Veh $N=15$; Blebb $N=15$; AMP: Veh $N=21$; Blebb $N=23 .\left(^{*}\right) P \leq 0.05,\left({ }^{* *}\right) P \leq 0.01,\left(^{* * *}\right) P \leq 0.001,\left(^{* * *}\right) P \leq 0.0001$. Error bars represent S.E.M. temic NMIIi may have disrupted the memory's reconsolidation. This is consistent with a demonstrated role for actin polymerization in the reconsolidation of other forms of memory (Mantzur et al. 2009; Rehberg et al. 2010; Ding et al. 2013; Li et al. 2015).

To further examine a potential reconsolidation effect, Blebb was administered immediately after Test 1 (Supplemental Fig. S1A). However, unlike following pre-Test 1 Blebb, COC place preference was unchanged at Test 2 with post-Test 1 Blebb (Supplemental Fig. S1B,C) (VEH: Test $\times$ Compartment: $F_{(2,24)}=13.14$, $P \leq 0.001$; Compartment: $F_{(1,12)}=1.755, P \leq 0.01$; Test: $F_{(2,24)}=$ 3.001, $P \leq 0.05$; Blebb: Test $\times$ Compartment: $F_{(2,28)}=11.99, P \leq$ 0.001; Compartment: $F_{(1,14)}=8.848, P \leq 0.01$; Test: $F_{(2,28)}=$ $7.174, P \leq 0.01)$. Post hoc results confirm that VEH and Blebb animals preferred the COC-paired compartment on both days. The apparently conflicting results between Blebb delivered immediately before or after Test 1 could indicate an acceleration of extinction learning, rather than a blockade of reconsolidation. This lymerization) is required for extinction learning (Fischer et al. 2004). However, we further assessed the possibility by examining performance over the course of testing on each day following preTest 1 Blebb (Supplemental Fig. S2A). In the case of accelerated exin, one would expect to see a loss of place preference during the 15 -min period of Test 1 or Test 2 . In the case of disrupted reconsolidation, one would expect to see normal place preference throughout Test 1 , followed by an absence of the place preference throughout the entire second test. VEH and Blebb-treated animals maintained their place preference throughout Test 1 (Supplemental Fig. S2B,C) VEH: Time $\times$ Compartment: $F_{(2,60)}=2.125$, $P>0.05$; Compartment: $F_{(1,30)}=17.64$, $P \leq 0.001$; Time: $F_{(2,60)}=0.8725, \quad P>$ 0.05; Blebb: Time $\times$ Compartment: $F_{(2,60)}=0.6938, P>0.05$; Compartment: $F_{(1,30)}=52.07, P \leq 0.0001$; Time: $F_{(2,60)}=$ $0.6746, P>0.05)$. Similar performance was seen in VEH animals during Test 2 (Supplemental Fig. S2D; Time $\times$ Compartment: $F_{(2,56)}=7.341, P \leq 0.01$; Compartment: $\quad F_{(1,28)}=13.85, \quad P \leq 0.001$; Time: $\left.F_{(2,56)}=0.1712, P>0.05\right)$. Blebb animals, on the other hand, showed a complete loss of the place preference from the start of Test 2, consistent with the interpretation that reconsolidation was disrupted, rather than extinction being accelerated by NMIIi (Supplemental Fig. S2E) (Blebb: Time $\times$ Compartment: $F_{(2,56)}=4.008, P \leq 0.01$; Compartment: $F_{(1,28)}=0.7098, P>0.05$; Time: $F_{(2,56)}=$ 1.005, $P>0.05)$.

To further assess the impact of NMIIi on drug-associated memory, we determined the effect of Blebb on a psychostimulant in the same class as METH, AMP. Similar to our prior findings with METH (Young et al. 2014, 2016), NMIIi resulted in an immediate disruption of AMP-associated memories that persisted into the second test (VEH: Test $\times$ Compartment: $\quad F_{(2,32)}=3.756$, $P \leq 0.05$; Compartment: $F_{(1,16)}=7.777$, $P \leq 0.05$; Test: $F_{(2,32)}=0.7230, P>0.05$; Blebb: Test $\times$ Compartment: $\quad F_{(2,40)}=$ 7.789, $P \leq 0.01$; Compartment: $F_{(1,20)}=$ $18.78, P \leq 0.001$; Test: $F_{(2,40)}=7.789$, $P>0.05)$. After finding an effect of 
Blebb on AMP-associated memories, we replicated the finding and the data were combined with the first cohort data (Fig. 1F,G) (VEH: Test $\times$ Compartment: $F_{(2,80)}=6.749, \quad P \leq 0.01$ Compartment: $F_{(1,40)}=16.60, P \leq 0.001$; Test: $F_{(2,80)}=1.167, P>0.05$; Blebb: Test $\times$ Compartment: $F_{(2,88)}=6.793, P \leq 0.01$; Compartment: $F_{(1,44)}=12.46, \quad P \leq 0.001$; Test: $\left.F_{(2,88)}=1.434, \quad P>0.05\right)$. In Figure $1 \mathrm{G}$, Blebb appears to produce an aversion to the CS+. Based on the positive MOR and COC place preferences displayed by Blebb-treated animals (Fig. 1C,E), it is highly unlikely that Blebb itself is aversive. Rather, the apparent aversion in AMPtrained, Blebb-treated mice reflects the design of our CPP experiments, in which AMP was paired with an individual animal's initially least preferred CPP chamber to avoid the false appearance of a drug-induced place preference post-training. As a result, when the memory is disrupted by Blebb, animals revert to a pattern closer to their pretraining preference for the CS- compartment (see Supplemental Table 1 for additional analysis). Taken together, these results suggest that immediate, NMII-mediated disruption of drug-associated memory may be limited to the amphetamine class.

In previous work, we reported that the density of dendritic spines increases in the BLC with METH conditioning and correlates with the strength of the memory (Young et al. 2014). Using tissue from these same Thy1-GFP mice(m), in which BLC spine density had been assessed following conditioning with METH or saline (Young et al. 2014), we determined spine density in CA1 and found an increase in METH-conditioned mice (Fig.
A
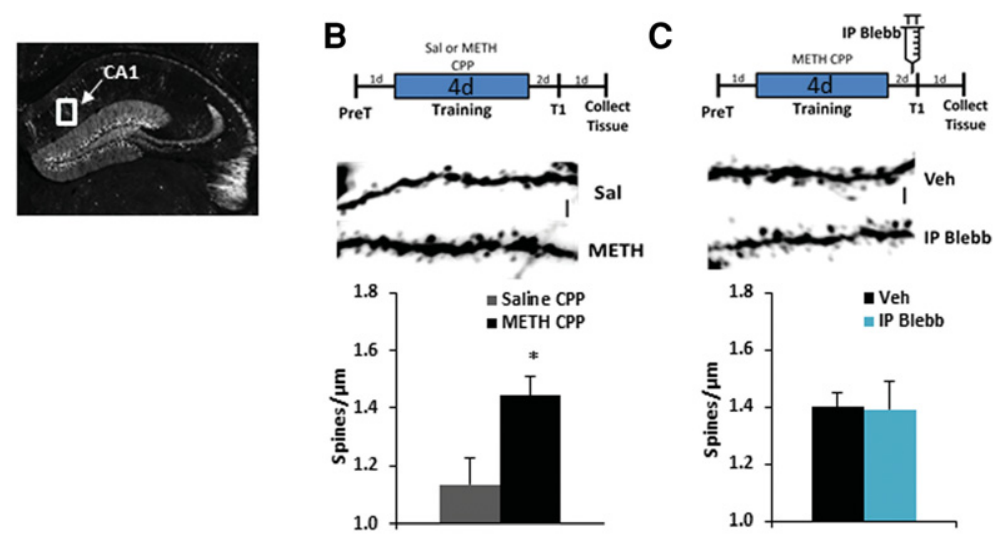

D

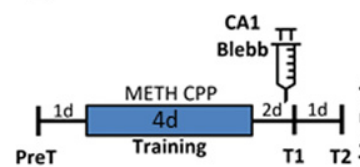

$$
\text { Pret }
$$$$
\text { Training }
$$

E Vehicle

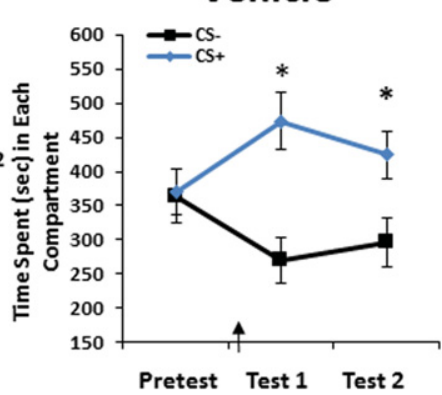

F Blebbistatin

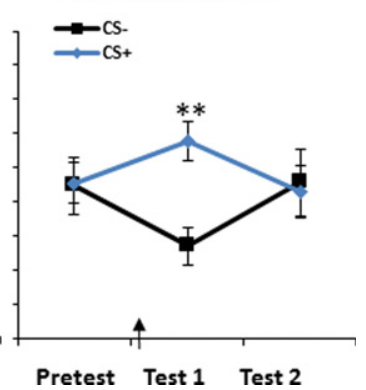

Figure 2. Intra-hippocampus NMII inhibition has no effect on spine density or the immediate expression of a METH-associated memory. (A) Location of dendritic spine density analysis within Area CA1 of the HPC. (B) The effect of METH-associated learning on spine density in CA1. (C) The effect of NMII inhibition on spine density in CA1 following METH-associated learning. (D) Schematic of experimental design. (E) The effect of intra-CA1 infusion of $(E)$ Vehicle or $(F)$ Blebb on METH-associated memory. Arrows indicate timing of Vehicle or Blebb infusion. 11 dendrites for each group were analyzed for spine density analysis. Intra-CA1: Veh $N=10$; Blebb $N=14 .\left(^{*}\right) P \leq 0.05,\left({ }^{* *}\right) P \leq 0.01$. Error bars represent S.E.M. $\left.2 \mathrm{~A}, \mathrm{~B} ; F_{(112)}=7.50, P \leq 0.05\right)$. We have also previously reported that NMIIi-mediated disruption of a METH-associated memory sity (Young et al. 2016). Using this same tissue, in which METH-associated memory was disrupted and BLC spine density reduced by systemic Blebb (Young et al. 2016), we assessed the impact on CA1 pine density. Unlike in the BLC, Blebb treatment had no effect on $\left.F_{(1,10)}=0.014, P>0.05\right)$.

If spine density is indeed related to the storage of METH-associated memory, this would predict that NMIIi in CA1 would fail to disrupt the memory. Indeed, unlike when infused nto the BLC (or given IP), intra-CA1 Blebb prior to Test 1 (Fig. y. However, similar to the effect of systemic Blebb on at Test 2 in Compartment: $F_{(2,36)}=4.643, P \leq 0.05$; Compartment: $F_{(1,18)}=$ 9.710, $P \leq 0.05$; Test $F_{(2,36)}=0.05748, P>0.05$; Blebb: Test $x$ Compartment: $F_{(2,52)}=5.490, P \leq 0.05$; Test: $F_{(2,52)}=0.06091$, infused into CA1 immediately following Test 1 both before VEH or Blebb treatment (Test 1), and after (Test 2) (Supplemental Fig. S3B,C, VEH: Test $\times$ Compartment: $F_{(2,20)}=$ 4.408, $P \leq 0.05$; Compartment: $F_{(1,10)}=5.292, P \leq 0.05$; Test: $F_{(2,20)}=0.4652, P>0.05$; Blebb: Test $\times$ Compartment: $F_{(2,28)}=3.819, P \leq 0.05$; Compartment: $F_{(1,14)}=10.44, P \leq 0.01$; Test: $\left.F_{(2,28)}=1.492, P>0.05\right)$, indicating a lack of NMIIi-mediated reconsolidation blockade when Blebb was delivered at this time point.

As with the COC-associated memory, the absence of a place preference at Test 2 in animals that received intra-CA1 Blebb prior to Test 1 could indicate an enhancement of extinction, rather than a disruption of reconsolidation. To investigate this, we assessed Test 1 and Test 2 (Supplemental Fig. S4A) place preference in 5-min bins. The VEH-treated group displayed a place preference throughout Test 1 and most of Test 2 (Supplemental Fig. S4B, Test 1: Time $\times$ Compartment: $\quad F_{(2,36)}=1.571$, $P>0.05$; Compartment: $F_{(1,18)}=14.15$, $P \leq 0.01$; Time: $\quad F_{(2,36)}=0.3007, \quad P>$ 0.05 ; Supplemental Fig. S4D, Test 2: Time $\times$ Compartment: $F_{(2,36)}=0.2021$, $P>0.05$; Compartment: $F_{(1,18)}=6.907$, $P \leq 0.05 ; \quad$ Time: $\quad F_{(2,36)}=0.5085, \quad P>$ 0.05). Blebb-treated animals also displayed a place preference throughout Test 1 (Supplemental Fig. S4C, Time $x$ Compartment: $F_{(2,52)}=1.959, P>0.05$; Compartment: $F_{(1,26)}=12.62, P \leq 0.01$; Time: $\left.\quad F_{(1,26)}=12.62, \quad P>0.05\right)$, but at no point during Test 2 (Supplemental Fig. S4E), (Time $\times$ Compartment: $F_{(2,36)}=4.469, P \leq 0.05$; Compartment: $F_{(1,18)}=0.2125, P>0.05$; Time: $F_{(2,36)}=$ $0.4508, P>0.05)$, consistent with a disruption of reconsolidation by pre-Test 1 intra-CA1 Blebb. 
To further assess the effect of NMIIi on METH-associated memory within the neural circuit, mice received intra-OFC or intra-NAcc infusions of Blebb $30 \mathrm{~min}$ prior to testing for METH-associated memory (Fig. 3A). Similar to CA1, intra-OFC infusion of Blebb had no effect on time spent in the drug-paired compartment (Fig. 3B,C, VEH: Test $\times$ Compartment: $F_{(2,44)}=6.889$, $P \leq 0.01$; Compartment: $F_{(1,22)}=5.874, P \leq 0.05$; Test: $F_{(2,44)}=$ $0.1399, P>0.05$; Blebb: Test $\times$ Compartment: $F_{(2,44)}=5.108$, $P \leq 0.01$; Compartment: $F_{(1,22)}=5.613, P \leq 0.05$; Test: $F_{(2,44)}=$ $0.4645, P>0.05)$. Further highlighting the unique nature of actin regulation in the BLC in association with METH memory, there was no immediate effect of Blebb in the NAcc either (Fig. 3D,E) VEH: Test $\times$ Compartment: $F_{(2,32)}=10.07, P \leq 0.001$; Compartment: $F_{(1,16)}=4.573, P \leq 0.05$; Test: $F_{(2,32)}=0.5367, P>0.05$; Blebb: Test $\times$ Compartment: $F_{(2,32)}=6.577, P \leq 0.05$; Compartment: $F_{(1,16)}=2.918, P>0.05$; Test: $\left.F_{(2,32)}=0.4481, P>0.05\right)$. Cannula placements for intra-CNS infusions can be found in Supplemental Figure S5. Together, these data suggest that Blebb's ability to immediately disrupt METH-associated memory may be unique to the BLC (Young et al. 2014, 2015, 2016).

We have previously reported that pharmacologic actin depolymerization, as well as pharmacologic and genetic inhibition of NMII within the BLC produces an immediate, retrieval-independent disruption of METH-associated memory storage. Further, these same manipulations have no effect on memories associated with footshock or food reward (Rex et al. 2010; Gavin et al. 2012; Young et al. 2014, 2016). Here, we extend these findings to show that the memory disrupting effects of NMIIi are even more selective than we initially hypothesized. Indeed, the only immediate disruption achieved by NMII inhibition was in the context of

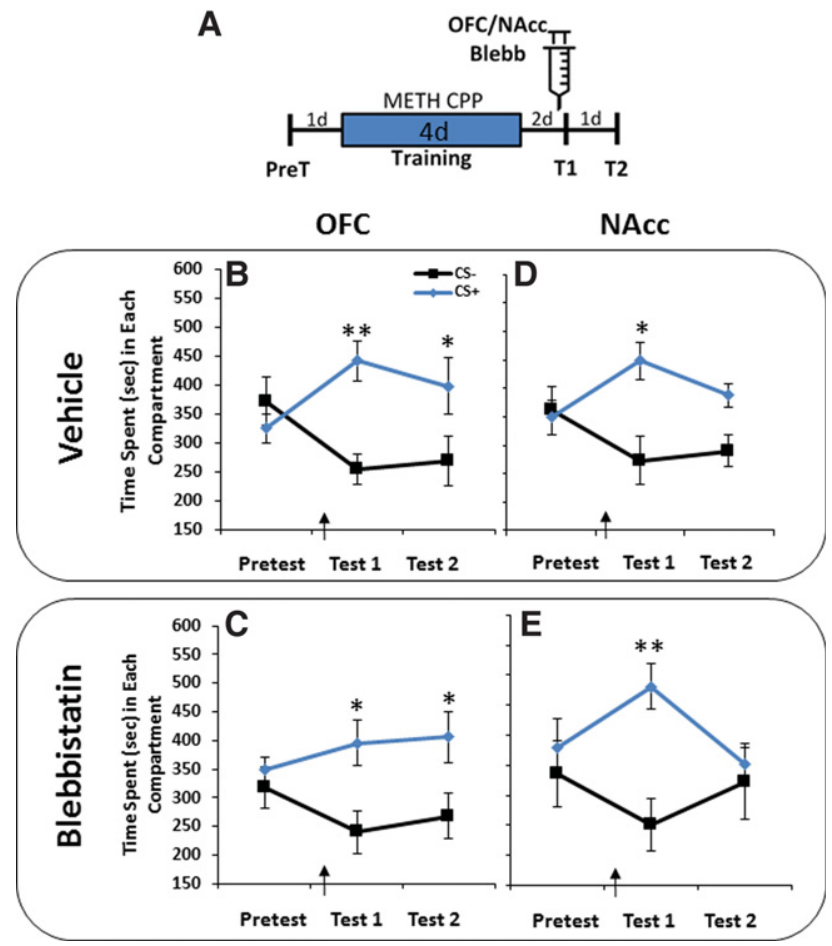

Figure 3. Inhibition of nonmuscle myosin II within the OFC or NAcc does not have an immediate effect on METH-associated memory. $(A)$ Schematic of experimental design. The effect of NMII inhibition by Blebbistatin within the $(B, C)$ OFC or $(D, E)$ NAcc on METH-associated memory. Arrows indicate timing of Vehicle or Blebb infusion. PFC: Veh $N=12$, Blebb $N=12$; NAc Veh $N=9$; Blebb $N=9 .\left(^{*}\right) P \leq 0.05$, ( $\left.{ }^{* *}\right)$ $P \leq 0.01$. Error bars represent S.E.M.
AMP-associated memory, which has important implications for the rising abuse of Adderall. Although COC, AMP, and METH are all psychostimulants, there are important differences that may underlie the specificity of NMIIi to members of the AMP class. First, the half-life of AMPs and COC differ significantly. In mice, COC has a relatively short half-life of $\sim 15$ min (Benuck et al. 1987), compared with $1 \mathrm{~h}$ for METH and AMP (Fuller et al. 1972; Brien et al. 1978). This disparity is even greater in humans, where COC has a half-life of $1 \mathrm{~h}$, while METH's half-life is roughly $12 \mathrm{~h}$ (Cook et al. 1993; Harris et al. 2003). AMP-like drugs are also unique from $\mathrm{COC}$, in that they bind and activate the trace amine-associated receptor 1 (TAAR1) (Bunzow et al. 2001)). This receptor colocalizes with monoamine transporters (Xie and Miller 2007, 2008; Lindemann et al. 2008) and is enriched in brain nuclei associated with reward, including the BLC (Borowsky et al. 2001). Thus, this receptor is uniquely positioned to mediate the effects of AMP-like drugs, though it does not explain the failure of NMIIi to disrupt METH-associated memory in the HPC, NAcc, or OFC, as TAAR1 is also expressed here. TAAR1 stimulation results in the internalization of monoamine transporters and enhanced DA efflux (Zucchi et al. 2006; Xie and Miller 2009a,b), contributing to the far greater levels of monoamines found in the synaptic cleft for longer periods of time with METH and AMP, relative to COC (Di Chiara and Imperato 1988; Xie and Miller 2009b). Further, actin dynamics are influenced by monoamines. For instance, repeated activation of the D1 dopamine receptor can produce dendritic remodeling, an actin-dependent process (Krucker et al. 2000; Fukazawa et al. 2003; Lin et al. 2013).

Given the broad reliance of many brain regions on actin polymerization for memory processes (for review, see Sorg 2012; Baldi and Bucherelli 2015), we hypothesized that the perpetual actin cycling following METH-associated learning that confers the selective, retrieval-independent susceptibility of the memory to disruption may not be limited to the BLC. Therefore, we investigated the potential for NMIIi to similarly disrupt METH-associated memory when infused directly into other regions of the neural circuit supporting the memory, the OFC, NAcc, and CA1. The lack of an immediate memory disrupting effect with NMIIi in any of these regions suggests that memory-related actin is likely stabilized after learning, similar to what we and others have previously demonstrated in the context of fear and food reward memories (Mantzur et al. 2009; Rehberg et al. 2010; Rex et al. 2010; Gavin et al. 2012; Young et al. 2014, 2016). Though it should be noted that, while the coordinates and infusion volume targeted the NAc core, spillover of Blebb into the shell may have occurred, raising the possibility that NMIIi produced opposing behavioral effects in the accumbens core and shell.

Given that systemic administration of Blebb failed to disrupt MOR and COC-associated memories and infusions of Blebb into the NAc, OFC, and CA1 failed to recapitulate the effect of infusion into the BLC, we tested animals a second time $24 \mathrm{~h}$ later to assess potential reconsolidation effects of NMIIi. The apparent blockade of COC-associated reconsolidation following pre-Test IP Blebb administration and METH-associated reconsolidation following NMII inhibition in CA1 prior to testing is not surprising, given that actin polymerization has been implicated in fear memory reconsolidation and these two brain regions have been implicated in the reconsolidation of memories associated with drugs of abuse, including COC (Miller and Marshall 2005; Monfils et al. 2009; Rehberg et al. 2010; Ding et al. 2013; Lee and Hynds 2013; Baldi and Bucherelli 2015; Li et al. 2015). To more directly investigate the potential reconsolidation effect of NMIIi, we used an experimental design more traditionally used to assess reconsolidation, by administering Blebb immediately after the first test. Manipulations at this time have proved effective for a number of molecular processes, such as protein synthesis, and a 
number of memory types, including those associated with drugs of abuse. Interestingly, post-retrieval NMIIi had no effect on the drug-associated memories at the second test. This result may not be as surprising as it first appears when one considers the rapid timing associated with plasticity-induced actin dynamics. Our understanding of spine actin dynamics in vivo, particularly in the BLC, is very limited, largely due to the technical challenges of imaging. However, insight into the temporal dynamics of actin polymerization can be gained from studies of long-term potentiation (LTP) in acute hippocampal slices. Actin polymerization is required for the stabilization of plasticity (Krucker et al. 2000; Fukazawa et al. 2003), and spine F-actin levels increase within just a few minutes of NMDA-induced activation in culture (Okamoto et al. 2004) or $\theta$ burst stimulation in slices (Kramar et al. 2006; Rex et al. 2009). The ability of actin depolymerization and NMIIi to disrupt LTP closely matches this rate of TBS-induced actin polymerization, such that Latrunculin A, an actin depolymerizer, or Blebb prevents LTP stabilization when applied 30 sec, but not $10 \mathrm{~min}$, after $\theta$ burst stimulation (Rex et al. 2010). This tight temporal window of efficacy is attributed to rapid stabilization of the actin cytoskeleton. The relevance of LTP to reconsolidation is underscored by studies showing that synaptic reactivation can resensitize LTP to protein synthesis inhibition (Fonseca et al. 2006; Okubo-Suzuki et al. 2016), much like reconsolidation. Thus, it is very likely that in the case of Blebb delivery after retrieval, either through infusions into CA1 (Supplemental Fig. S3) or systemically (Supplemental Fig. S1), the window for targeting actin dynamics via inhibition of its upstream regulator, NMII, had already closed by the time Blebb reached the brain region of interest and penetrated the cells to interfere with actin polymerization.

This inability to disrupt contextual drug memories with postretrieval Blebb treatment leaves open the possibility that the lack of a place preference at the second test following pre-Test Blebb was due to an acceleration of extinction, rather than a blockade of reconsolidation. However, the reconsolidation interpretation is supported in two ways. First, stable place preferences are present throughout Test 1 in the COC and CA1 experiments, but absent from the start of Test 2 . In the case of accelerated extinction, one would expect to see a rapid decline during the course of one of the two 15 min test periods, which is not the case. In addition, actin polymerization is required for extinction learning (Fischer et al. 2004), such that inhibiting polymerization during extinction training results in protection of the original memory trace. Here we report the opposite effect of depolymerization via NMIIi, a loss of drug memories. Taken together, these results extend our understanding of actin-mediated signaling in reconsolidation by implicating its direct upstream regulator, NMII. Further, the results suggest that NMIIi may prove to be a powerful therapeutic approach for disrupting memories associated with amphetamines by their selective targeting in storage, but also other psychostimulants if delivered in the context of memory reactivation.

\section{Acknowledgments}

The authors thank the Scripps Florida Behavior Core for providing behavioral equipment and Colton Hoffer for technical assistance. This work was supported by grants from the National Institute on Drug Abuse to C.A.M. (R01DA034116 and R01DA03411603S1 Diversity Supplement to support S.B.B.) and A.M.B. (K01DA040737), as well as the Brain and Behavior Research Foundation to A.M.B. (NARSAD Young Investigator Award).

\section{References}

Aguilar-Valles A, Vaissière T, Griggs EM, Mikaelsson MA, Takács IF, Young EJ, Rumbaugh G, Miller CA. 2014.
Methamphetamine-associated memory is regulated by a writer and an eraser of permissive histone methylation. Biol Psychiatry 76: 57-65.

Baldi E, Bucherelli C. 2015. Brain sites involved in fear memory reconsolidation and extinction of rodents. Neurosci Biobehav Rev 53: $160-190$.

Baracz SJ, Rourke PI, Pardey MC, Hunt GE, McGregor IS, Cornish JL. 2012 Oxytocin directly administered into the nucleus accumbens core or subthalamic nucleus attenuates methamphetamine-induced conditioned place preference. Behav Brain Res 228: 185-193.

Benuck M, Lajtha A, Reith ME. 1987. Pharmacokinetics of systemically administered cocaine and locomotor stimulation in mice. J Pharmacol Exp Ther 243: 144-149.

Bi AL, Wang Y, Zhang S, Li BQ, Sun ZP, Bi HS, Chen ZY. 2015. Myosin II regulates actin rearrangement-related structural synaptic plasticity during conditioned taste aversion memory extinction. Brain Struct Funct 220: 813-825.

Borowsky B, Adham N, Jones KA, Raddatz R, Artymyshyn R, Ogozalek KL, Durkin MM, Lakhlani PP, Bonini JA, Pathirana S, et al. 2001. Trace amines: identification of a family of mammalian $\mathrm{G}$ protein-coupled receptors. Proc Natl Acad Sci 98: 8966-8971.

Brien JF, Kitney JC, Peachey JE, Rogers BJ. 1978. Methamphetamineinduced behavioural effects and brain concentrations of methamphetamine and its metabolite amphetamine in mice. Res Commun Chem Pathol Pharmacol 22: 313-328.

Bunzow JR, Sonders MS, Arttamangkul S, Harrison LM, Zhang G, Quigley DI, Darland T, Suchland KL, Pasumamula S, Kennedy JL, et al. 2001. Amphetamine, 3,4-methylenedioxymethamphetamine, lysergic acid diethylamide, and metabolites of the catecholamine neurotransmitters are agonists of a rat trace amine receptor. $\mathrm{Mol}$ Pharmacol 60: 1181-1188.

Chiang CY, Cherng CG, Lai YT, Fan HY, Chuang JY, Kao GS, Chang WT, Yu L. 2009. Medial prefrontal cortex and nucleus accumbens core are involved in retrieval of the methamphetamine-associated memory. Behav Brain Res 197: 24-30.

Cook CE, Jeffcoat AR, Hill JM, Pugh DE, Patetta PK, Sadler BM, White WR, Perez-Reyes M. 1993. Pharmacokinetics of methamphetamine self-administered to human subjects by smoking S-(+)-methamphetamine hydrochloride. Drug Metab Dispos 21: $717-723$.

Di Chiara G, Imperato A. 1988. Drugs abused by humans preferentially increase synaptic dopamine concentrations in the mesolimbic system of freely moving rats. Proc Natl Acad Sci 85: 5274-5278.

Ding ZB, Wu P, Luo YX, Shi HS, Shen HW, Wang SJ, Lu L. 2013. Region-specific role of Rac in nucleus accumbens core and basolateral amygdala in consolidation and reconsolidation of cocaine-associated cue memory in rats. Psychopharmacology (Berl) 228: 427-437.

Fischer A, Sananbenesi F, Schrick C, Spiess J, Radulovic J. 2004. Distinct roles of hippocampal de novo protein synthesis and actin rearrangement in extinction of contextual fear. J Neurosci 24: 1962-1966.

Fonseca R, Nagerl UV, Bonhoeffer T. 2006. Neuronal activity determines the protein synthesis dependence of long-term potentiation. Nat Neurosci 9: $478-480$.

Fukazawa Y, Saitoh Y, Ozawa F, Ohta Y, Mizuno K, Inokuchi K. 2003. Hippocampal LTP is accompanied by enhanced F-actin content within the dendritic spine that is essential for late LTP maintenance in vivo. Neuron 38: 447-460.

Fuller RW, Molloy BB, Roush BW, Hauser KM. 1972. Disposition and behavioral effects of amphetamine and, -difluoroamphetamine in mice. Biochem Pharmacol 21: 1299-1307.

Gavin CF, Rubio MD, Young E, Miller C, Rumbaugh G. 2012. Myosin II motor activity in the lateral amygdala is required for fear memory consolidation. Learn Mem 19: 9-14.

Harris DS, Boxenbaum H, Everhart ET, Sequeira G, Mendelson JE, Jones RT. 2003. The bioavailability of intranasal and smoked methamphetamine. Clin Pharmacol Ther 74: 475-486.

Hyman SE, Malenka RC, Nestler EJ. 2006. Neural mechanisms of addiction: the role of reward-related learning and memory. Annu Rev Neurosci 29: $565-598$.

Keleta YB, Martinez JL. 2012. Brain circuits of methamphetamine place reinforcement learning: the role of the hippocampus-VTA loop. Brain Behav 2: 128-141.

Kramar EA, Lin B, Rex CS, Gall CM, Lynch G. 2006. Integrin-driven actin polymerization consolidates long-term potentiation. Proc Natl Acad Sci 103: $5579-5584$.

Krucker T, Siggins GR, Halpain S. 2000. Dynamic actin filaments are required for stable long-term potentiation (LTP) in area CA1 of the hippocampus. Proc Natl Acad Sci 97: 6856-6861.

Lai CSW, Franke TF, Gan WB. 2012. Opposite effects of fear conditioning and extinction on dendritic spine remodelling. Nature 483: 87-91. 
Lee JL, Hynds RE. 2013. Divergent cellular pathways of hippocampal memory consolidation and reconsolidation. Hippocampus 23: 233-244.

Lee JL, Di Ciano P, Thomas KL, Everitt BJ. 2005. Disrupting reconsolidation of drug memories reduces cocaine-seeking behavior. Neuron 47: 795-801.

Li G, Wang Y, Yan M, Xu Y, Song X, Li Q, Zhang J, Ma H, Wu Y. 2015. Inhibition of actin polymerization in the NAc shell inhibits morphine-induced CPP by disrupting its reconsolidation. Sci Rep 5: 16283.

Lin B, Kramar EA, Bi XN, Brucher FA, Gall CM, Lynch G. 2005. Theta stimulation polymerizes actin in dendritic spines of hippocampus. $J$ Neurosci 25: 2062-2069.

Lin YC, Yeckel MF, Koleske AJ. 2013. Abl2/Arg controls dendritic spine and dendrite arbor stability via distinct cytoskeletal control pathways. J Neurosci 33: 1846-1857.

Lindemann L, Meyer CA, Jeanneau K, Bradaia A, Ozmen L, Bluethmann H, Bettler B, Wettstein JG, Borroni E, Moreau JL, et al. 2008. Trace amine-associated receptor 1 modulates dopaminergic activity. $J$ Pharmacol Exp Ther 324: 948-956.

Mantzur L, Joels G, Lamprecht R. 2009. Actin polymerization in lateral amygdala is essential for fear memory formation. Neurobiol Learn Mem 91: $85-88$.

Miller CA, Marshall JF. 2005. Molecular substrates for retrieval and reconsolidation of cocaine-associated contextual memory. Neuron 47: $873-884$.

Milton AL, Everitt BJ. 2012. The persistence of maladaptive memory: addiction, drug memories and anti-relapse treatments. Neurosci Biobehav Rev 36: 1119-1139.

Monfils MH, Cowansage KK, Klann E, LeDoux JE. 2009. Extinctionreconsolidation boundaries: key to persistent attenuation of fear memories. Science 324: 951-955.

Okamoto K, Nagai T, Miyawaki A, Hayashi Y. 2004. Rapid and persistent modulation of actin dynamics regulates postsynaptic reorganization underlying bidirectional plasticity. Nat Neurosci 7: 1104-1112.

Okubo-Suzuki R, Saitoh Y, Shehata M, Zhao Q, Enomoto H, Inokuchi K. 2016. Frequency-specific stimulations induce reconsolidation of long-term potentiation in freely moving rats. Mol Brain 9: 36.

Rehberg K, Bergado-Acosta JR, Koch JC, Stork O. 2010. Disruption of fear memory consolidation and reconsolidation by actin filament arrest in the basolateral amygdala. Neurobiol Learn Mem 94: 117-126.

Rex CS, Chen LY, Sharma A, Liu J, Babayan AH, Gall CM, Lynch G. 2009. Different Rho GTPase-dependent signaling pathways initiate sequential steps in the consolidation of long-term potentiation. J Cell Biol 186: 85-97.

Rex CS, Gavin CF, Rubio MD, Kramar EA, Chen LY, Jia Y, Huganir RL, Muzyczka N, Gall CM, Miller CA, et al. 2010. Myosin IIb regulates actin dynamics during synaptic plasticity and memory formation. Neuron 67: $603-617$.
Ricoy UM, Martinez JL Jr. 2009. Local hippocampal methamphetamineinduced reinforcement. Front Behav Neurosci 3: 47.

Sorg BA. 2012. Reconsolidation of drug memories. Neurosci Biobehav Rev 36: $1400-1417$.

Taylor JR, Olausson P, Quinn JJ, Torregrossa MM. 2009. Targeting extinction and reconsolidation mechanisms to combat the impact of drug cues on addiction. Neuropharmacology 56(Suppl 1): 186-195.

Torregrossa MM, Taylor JR. 2013. Learning to forget: manipulating extinction and reconsolidation processes to treat addiction. Psychopharmacology (Berl) 226: 659-672.

Tronson NC, Taylor JR. 2013. Addiction: a drug-induced disorder of memory reconsolidation. Curr Opin Neurobiol 23: 573-580.

Xie Z, Miller GM. 2007. Trace amine-associated receptor 1 is a modulator of the dopamine transporter. J Pharmacol Exp Ther 321: 128-136.

Xie Z, Miller GM. 2008. $\beta$-Phenylethylamine alters monoamine transporter function via trace amine-associated receptor 1: implication for modulatory roles of trace amines in brain. J Pharmacol Exp Ther 325: 617-628.

Xie Z, Miller GM. 2009a. A receptor mechanism for methamphetamine action in dopamine transporter regulation in brain. J Pharmacol Exp Ther 330: 316-325.

Xie Z, Miller GM. 2009b. Trace amine-associated receptor 1 as a monoaminergic modulator in brain. Biochem Pharmacol 78: $1095-1104$.

Yang G, Pan F, Gan WB. 2009. Stably maintained dendritic spines are associated with lifelong memories. Nature 462: 920-924.

Young EJ, Aceti M, Griggs EM, Fuchs RA, Zigmond Z, Rumbaugh G, Miller CA. 2014. Selective, retrieval-independent disruption of methamphetamine-associated memory by actin depolymerization. Biol Psychiatry 75: 96-104.

Young EJ, Briggs SB, Miller CA. 2015. The actin cytoskeleton as a therapeutic target for the prevention of relapse to methamphetamine use. CNS Neurol Disord Drug Targets 14: 731-737.

Young EJ, Blouin AM, Briggs SB, Sillivan SE, Lin L, Cameron MD, Rumbaugh G, Miller CA. 2016. Nonmuscle myosin IIB as a therapeutic target for the prevention of relapse to methamphetamine use. Mol Psychiatry 21: 615-623.

Zhao Y, Liu P, Chu Z, Liu F, Han W, Xun X, Dang YH. 2015. Electrolytic lesions of the bilateral ventrolateral orbital cortex inhibit methamphetamine-associated contextual memory formation in rats. Brain Res 1624: 214-221.

Zucchi R, Chiellini G, Scanlan TS, Grandy DK. 2006. Trace amine-associated receptors and their ligands. Br J Pharmacol 149: 967-978.

Received September 8, 2016; accepted in revised form November 23, 2016. 


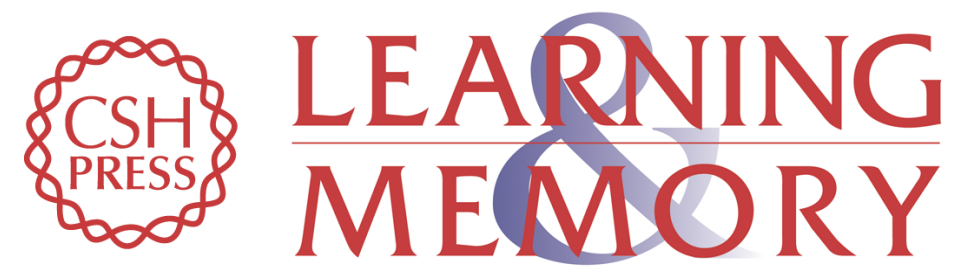

\section{Memory disrupting effects of nonmuscle myosin II inhibition depend on the class of abused drug and brain region}

Sherri B. Briggs, Ashley M. Blouin, Erica J. Young, et al.

Learn. Mem. 2017, 24:

Access the most recent version at doi:10.1101/Im.043976.116

\section{Supplemental http://learnmem.cshlp.org/content/suppl/2017/01/11/24.2.70.DC1 Material}

References This article cites 53 articles, 16 of which can be accessed free at: http://learnmem.cshlp.org/content/24/2/70.full.html\#ref-list-1

Creative This article is distributed exclusively by Cold Spring Harbor Laboratory Press for the Commons first 12 months after the full-issue publication date (see

License http://learnmem.cshlp.org/site/misc/terms.xhtml). After 12 months, it is available under a Creative Commons License (Attribution-NonCommercial 4.0 International), as described at http://creativecommons.org/licenses/by-nc/4.0/.

Email Alerting Receive free email alerts when new articles cite this article - sign up in the box at the Service top right corner of the article or click here. 